Volume 3 Nomor 1 halaman 19 - 27

ISSN: 2089-6026

\title{
Identifikasi Daun Shorea menggunakan KNN dengan Ekstraksi Fitur 2DPCA
}

\section{Shorea Leaves Identification using KNN with 2DPCA Feature Extraction}

\author{
ERNI YUSNIAR, AZIZ KUSTIYO*
}

\begin{abstract}
Abstrak
Shorea adalah jenis meranti yang memiliki nilai ekonomis yang tinggi. Shorea tergolong dalam famili Dipterocarpaceae yang memiliki 194 spesies yang tumbuh di daerah tropis. Shorea merupakan jenis yang sulit untuk diidentifikasi karena memiliki banyak kemiripan. Untuk mengatasi kesulitan tersebut, penelitian ini mengidentifikasi Shorea berdasarkan citra daun. Jumlah spesies yang digunakan penelitian ini adalah 10 jenis Shorea. Metode ekstraksi fitur yang digunakan adalah 2 dimensional principal component analysis (2D-PCA) dengan metode klasifikasi KNN. Penelitian ini memiliki 4 percobaan yang dibagi menjadi komponen R, G, B, dan grayscale. Hasil rata-rata akurasi terbaik sebesar 75\% pada komponen G dengan kontribusi nilai eigen $85 \%$.
\end{abstract}

Kata kunci: 2 Dimensional Principal Component Analysis, K-Nearest Neighbour, Shorea

\begin{abstract}
Shorea is a kind of meranti species that have high economic value. Shorea belongs to Dipterocarpaceae family which has 194 species that usually grow in tropical area. Shorea is difficult to be identified due to their similarity. To overcome these difficulties, this research attempted to identify Shorea based on leaf image. Feature extraction method used in this research is 2 dimensional principal component analysis while with KNN as classifier.This research conducted four trials that were divided into $R, G, B$, and grayscale components. The best average accuracy obtained was $75 \%$ on a $G$ component with $85 \%$ contribution of eigen values.
\end{abstract}

Keywords: 2 Dimensional Principal Component Analysis, K-Nearest Neighbour, Shorea

\section{PENDAHULUAN}

Shorea merupakan tumbuhan berkayu yang termasuk jenis meranti. Shorea tergolong dalam famili Dipterocarpaceae yang memiliki 194 spesies yang tumbuh di daerah tropis. Spesies tersebut menyebar secara alami mulai Semenanjung Thailand dan Malaysia, Sumatera, sampai Kalimantan Utara. Dipterocarpaceae merupakan jenis yang sulit untuk diidentifikasi, khususnya di daerah Kalimantan yang memiliki jenis terbanyak. Ketidakmampuan untuk mengenal individu Dipterocarpaceae di hutan dapat mengakibatkan terjadinya eksploitasi, khususnya meranti merah Shorea (Newman et al. 1999).

Jenis kayu Shorea yang memiliki nilai ekonomis yang tinggi juga menjadi salah satu faktor yang mengakibatkan terjadinya eksploitasi terhadap Shorea, khususnya jenis Shorea yang memiliki kualitas kayu yang baik. Untuk mencegah eksploitasi yang dapat disebabkan oleh kesalahan dalam pemilihan kayu yang tidak tepat, suatu sistem yang dapat mengidentifikasi jenis Shorea dengan tepat dibutuhkan. 
Identifikasi jenis Shorea dapat dilakukan dengan menggunakan batang, daun, buah, dan bunga. Jika menggunakan batang, dengan semakin bertambahnya umur pohon, warna dan kedalaman alurnya akan mengalami perubahan. Identifikasi menggunakan buah dan bunga sulit dilakukan karena buah dan bunga tumbuh secara musiman. Oleh karena itu, untuk memudahkan identifikasi Shorea, objek identifikasi yang dipilh pada penelitian ini adalah daun. Daun dipilih karena mudah menjadi objek pengamatan dan tersedia sepanjang waktu sehingga objek pengamatan

Penelitian terkait identifikasi Shorea pernah dilakukan oleh Ramadhan (2012) berdasarkan citra daun dengan ekstraksi fitur transformasi wavelet diskret dan fitur warna HSV menggunakan jaringan saraf tiruan. Transformasi wavelet digunakan sebagai ekstraksi fitur dan mereduksi ukuran citra. Akurasi yang diperoleh dari penelitian tersebut adalah 93.3\%.

Penelitian ini menggunakan ekstraksi fitur 2 Dimensional Principal Component Analysis (2DPCA) dengan K-Nearest Neighbour sebagai classifier. Ekstraksi fitur 2DPCA ini digunakan sebagai metode pengolahan citra daun yang dapat mereduksi ukuran citra. Selain itu, matriks kovarian yang dihasilkan juga terbentuk secara langsung dari citra daun sehingga ukuran matriks kovarian lebih kecil dan memudahkan proses evaluasi akurasi (RodríguezAragón et al. 2005).

Pada metode 2DPCA, citra daun asli tidak perlu diubah menjadi vektor kolom berukuran besar sehingga prosesnya lebih cepat dibanding metode Principal Component Analysis (PCA) yang harus mengubah citra daun asli menjadi vektor kolom terlebih dahulu.Penelitian yang terkait dengan 2DPCA antara lain dilakukan oleh Pratiwi (2010) tentang pengembangan model pengenalan wajah dengan jarak Euclid pada ruang eigen dengan 2DPCA dengan nilai akurasi tertinggi sebesar $98.75 \%$.

Penelitian ini menerapkan teknik ekstraksi fitur menggunakan 2 Dimensional Principal Component Analysis dan teknik klasifikasi K-Nearest Neighbour (KNN) untuk pengenalan citra daun Shorea. Penelitian ini menggunakan citra daun dari 10 spesies Shorea. Masingmasing spesies memiliki 10 citra daun sehingga total data citra daun berjumlah 100 citra daun. Hasil penelitian ini diharapkan dapat memudahkan identifikasi jenis Shorea berdasarkan citra daunnya.

\section{METODE}

Penelitian ini dilakukan dengan beberapa tahapan proses (Gambar 1) untuk mengetahui tingkat akurasi yang diperoleh menggunakan ekstraksi fitur 2DPCA dan klasifikasi KNN dalam pengidentifikasian daun Shorea.

\section{Pengumpulan Citra Daun}

Proses pengumpulan citra daun ini dilakukan dengan mengambil sejumlah citra daun secara langsung dengan menggunakan kamera digital. Citra Shorea yang digunakan dalam penelitian ini diambil pada siang hari di dalam ruangan. Citra daun tersebut diberikan latar belakang kertas putih untuk dijadikan citra percobaan, baik untuk pelatihan maupun pengujian.

\section{Citra Daun}

Data yang akan digunakan pada penelitian ini adalah data citra daun Shorea dengan 10 spesies berformat JPEG. Data citra asli daun Shorea ini berukuran $2736 \times 3648$ piksel. Citra yang digunakan pada penelitian ini adalah citra daun Shorea yang sampelnya diambil dari Kebun Raya Bogor. Data citra yang digunakan dalam penelitian ini merupakan data yang sama dengan data Ramadhan (2012). 


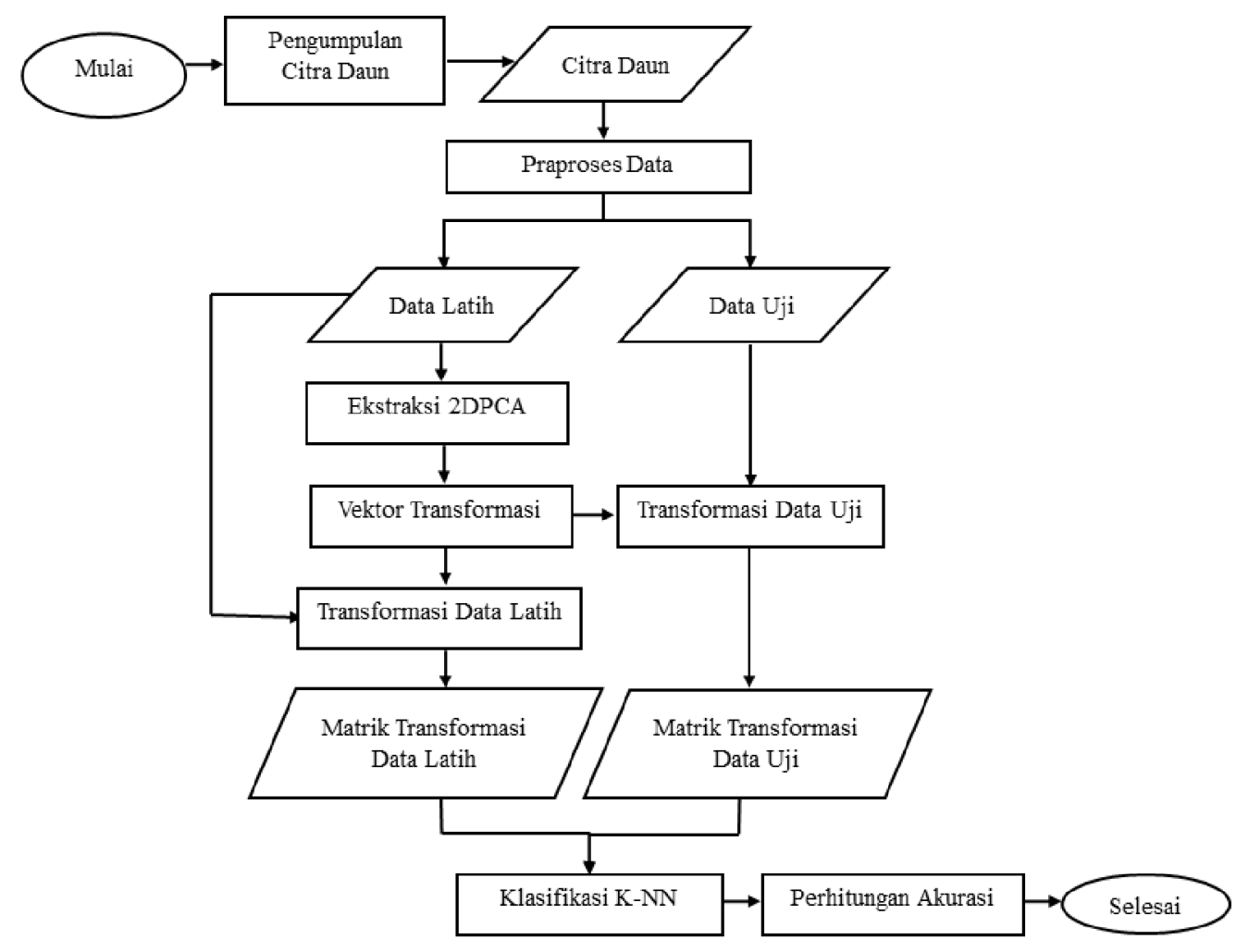

Gambar 1 Metodologi penelitian

\section{Praproses Data}

Pada penelitian ini sebelum dilakukan praproses, citra yang digunakan diubah terlebih dahulu arah daunnya menjadi searah. Model warna yang digunakan adalah model warna RGB dan grayscale. Model warna RGB akan dipisahkan, masing-masing menjadi komponen R, G, dan B. Setelah itu, ukuran citra yang semula berukuran $2736 \times 3648$ piksel akan di-resize menjadi $137 \times 182$. Proses resize dilakukan pada citra RGB dan grayscale. Grayscale berguna untuk ekstraksi citra menggunakan 2DPCA. Selain itu, grayscale juga dapat menyederhanakan model citra agar nilai yang dihasilkan tidak beragam.

\section{Data Latih dan Data Uji}

Data citra daun Shorea dibagi menjadi 2 bagian adalah data latih dan data uji. Penelitian ini menggunakan 10 citra daun Shorea untuk masing-masing 10 spesies. Dari 10 citra daun tersebut, 8 citra diambil untuk data latih dan 2 citra untuk data uji dengan 5-fold crossvalidation.

\section{Ekstraksi dengan 2DPCA}

Proses ekstraksi ciri citra daun dilakukan dengan menggunakan 2DPCA. Sebelum masuk ke ekstraksi 2DPCA, citra dipraproses terlebih dahulu. Ekstraksi dengan 2DPCA dilakukan untuk mereduksi dimensi fitur. Dari hasil ekstraksi dengan 2DPCA, diperoleh komponen utama berupa vektor eigen dan matriks transformasi. Vektor eigen diperoleh dengan mengambil nilai eigen yang terbesar yang dianggap mewakili dari kumpulan data yang ada. Vektor eigen ini diperoleh dari matriks kovarian untuk semua data latih yang ada. Di awal ekstraksi 2DPCA, semua rata-rata citra data latih dicari terlebih dahulu. Ilustrasi proses tersebut dapat dilihat pada Gambar 2.

Setelah matriks rataan didapatkan, matriks kovarian untuk citra data latih dicari dengan rumus berikut:

$$
G_{t}=\frac{1}{M} \sum_{j=1}^{M}\left(A_{j}-\bar{A}\right)^{T}\left(A_{j}-\bar{A}\right)
$$


$\mathrm{G}_{\mathrm{t}}$ akan berukuran $n \times n$ dan $M$ adalah jumlah citra data latih pada penelitian ini (80 citra). $A_{j}$ merupakan citra data latih yang digunakan dan $\bar{A}$ adalah rata-rata data dari semua data latih. Kemudian, nilai eigen dari matriks kovarian tersebut yang mewakili karakteristik citra didapatkan. Dari nilai eigen tersebut vektor eigen yang akan menghasilkan matriks ciri dari citra daun dapat dicari.

\section{Vektor Transformasi}

Pada vektor transformasi digunakan vektor eigen yang dari hasil proses 2DPCA. Vektor eigen ini akan direduksi sesuai dengan kontribusi nilai eigen yang digunakan pada penelitian ini. Hasil dari vektor transformasi ini adalah vektor eigen yang telah direduksi yang akan menjadi masukan pada tahap pembuatan transformasi data latih dan transformasi data uji.

\section{Transformasi Data Latih}

Transformasi data latih ini dilakukan untuk mengubah dimensi data latih yang akan digunakan. Data latih tersebut akan mengalami pengurangan dimensi karena proses reduksi vektor eigen.

\section{Matriks Transformasi Data Latih}

Data latih citra daun Shorea sebanyak 8 citra pada masing-masing 10 spesies akan dikalikan dengan transformasi data latih yang berasal dari hasil perhitungan pada citra data latih sebelumnya. Ilustrasi proses pembuatan matriks transformasi data latih dapat dilihat pada Gambar 3.

Setiap data latih dikalikan dengan vektor transformasi. A merupakan citra data latih dan $B$ adalah matriks hasil transformasi, sedangkan $X$ adalah matriks transformasi data latih yang didapatkan dari vektor transformasi yang telah direduksi sesuai dengan kontribusi nilai eigen yang digunakan.

\section{Transformasi Data Uji}

Transformasi data uji ini dilakukan agar data uji yang digunakan memiliki dimensi yang sama dengan data latih yang telah diproses sebelumnya. Data uji ini akan diproses lebih lanjut pada tahapan selanjutnya.

\section{Matriks Transformasi Data Uji}

Matriks transformasi data uji ini dibuat dari transformasi data uji yang telah direduksi

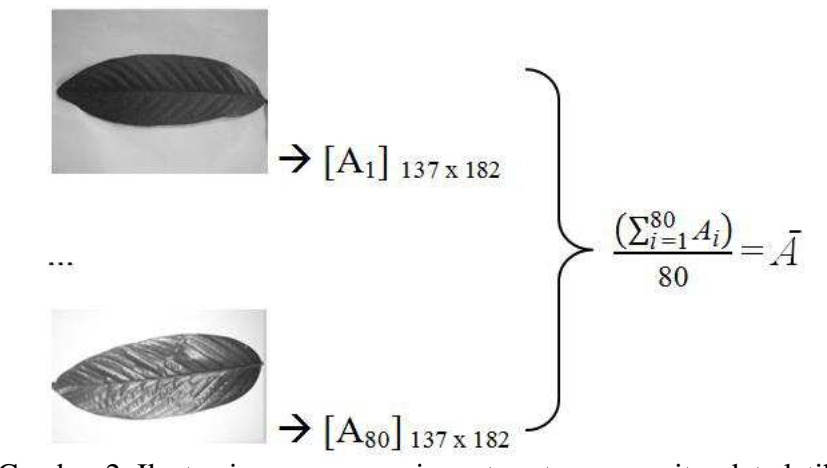

Gambar 2 Ilustrasi proses pencarian rata-rata semua citra data latih

$$
\begin{array}{lll}
{\left[\mathrm{A}_{1}\right]_{137 \times 182}} & \ldots & \rightarrow \mathrm{B}_{1}=\mathrm{A}_{1} \mathrm{X} \\
{\left[\mathrm{A}_{40}\right]_{137 \times 182}} & \ldots & \rightarrow \mathrm{B}_{40}=\mathrm{A}_{40} \mathrm{X} \\
{\left[\mathrm{A}_{80}\right]_{137 \times 182}} & \ldots & \rightarrow \mathrm{B}_{80}=\mathrm{A}_{80} \mathrm{X}
\end{array}
$$


dan diperoleh dari hasil proses 2DPCA pada data latih. Setiap citra daun yang akan diuji nantinya akan dikalikan dengan vektor eigen untuk mendapatkan matriks transformasinya.

\section{Klasifikasi KNN}

Metode klasifikasi yang dipakai pada penelitian ini adalah $K$-Nearest Neighbour (KNN) yang merupakan salah satu teknik klasifikasi yang membandingkan data uji yang diberikan dengan data latih untuk diklasifikasikan berdasarkan kedekatannya yang didefinisikan dengan ukuran jarak. Jarak diukur menggunakan jarak Euclidean yang merupakan pengukuran jarak garis lurus antara satu titik dengan titik lain, dalam hal ini jarak antara vektor kolom dalam matriks.

Diberikan dua matriks berikut:

$$
\mathrm{T}_{i}=\left[\mathrm{Y}_{1}^{i}, \mathrm{Y}_{2}^{i}, \ldots, \mathrm{Y}_{d}^{i}\right] \text { dan } \mathrm{T}_{j}=\left[\mathrm{Y}_{1}^{j}, \mathrm{Y}_{2}^{j}, \ldots, \mathrm{Y}_{d}^{j}\right]
$$

Jarak kedua matriks tersebut ialah

$$
d\left(\mathrm{~T}_{i}, \mathrm{~T}_{j}\right)=\sum_{k=1}^{d}\left\|\mathrm{Y}_{k}^{(i)}-\mathrm{Y}_{k}^{(j)}\right\|_{2}
$$

dengan

$$
\left\|\mathrm{Y}_{k}^{(i)}-\mathrm{Y}_{k}^{(j)}\right\|_{2}=\sqrt{\left(\mathrm{Y}_{k}^{(1 \mathrm{D})}-\mathrm{Y}_{\bar{k}}^{(1 /))^{2}}+\ldots\left(\mathrm{Y}_{k}^{(\mathrm{nin})}-\mathrm{Y}_{k}^{(\mathrm{n}))^{2}}\right.\right.}
$$

$\mathrm{Y}_{k}^{(i)}$ menyatakan data uji dan $\mathrm{Y}_{k}^{(j)}$ menyatakan data latih, serta $\mathrm{Y}_{k}^{(i)}-\mathrm{Y}_{k}^{(j)}$ menyatakan selisih dari data uji dengan data latih (Yang dan Zhang 2004).

\section{Perhitungan Akurasi}

Pada tahap ini, nilai akurasi berdasarkan data hasil klasifikasi menggunakan jarak Euclidean dihitung agar performa klasifikasi dapat diketahui. Tingkat akurasi dapat dihitung dengan cara:

$$
\text { Akurasi }=\frac{\sum \text { data uji benar diklasifikasikan }}{\sum \text { data uji }} \times 100 \%
$$

\section{HASIL DAN PEMBAHASAN}

Pada penelitian ini digunakan 10 spesies daun Shorea adalah Shorea javanica, Shorea johorensis, Shorea lepida, Shorea leprosula, Shorea marcoptera, Shorea materialis, Shorea palembanica, Shorea pinanga, Shorea platycados, dan Shorea seminis. Penelitian ini menggunakan komponen warna R, G, B, dan grayscale serta dikombinasikan dengan 3 kontribusi nilai adalah $85 \%, 95 \%$, dan $99 \%$. Klasifikasinya menggunakan KNN dengan nilai $k$ $=1,3,5$ dan 7 .

Pada tahap awal, praproses dilakukan terhadap citra data latih dilakukan dan dilanjutkan dengan ekstraksi 2DPCA. Proses ekstraksi 2DPCA menghasilkan matriks kovarian berukuran $182 \times 182$ dan menghasilkan 182 nilai eigen dan vektor eigen dengan ukuran $182 \times 182$. Kontribusi nilai eigen yang digunakan pada penelitian ini adalah $85 \%, 95 \%$, dan $99 \%$ dengan ukuran vektor eigen setelah direduksi dapat dilihat pada Tabel 1.

Vektor eigen yang diperoleh kemudian dikalikan dengan data citra baru sebagai data uji yang berukuran $137 \times 182$, ukuran citra yang akan dihasilkan untuk 3 kontribusi nilai eigen yang digunakan dapat dilihat pada Tabel 2 .

\section{Percobaan Komponen R, G, B, dan Grayscale}

Hasil akurasi yang diperoleh dari percobaan komponen R, G, B, dan grayscale yang dikombinasikan dengan 3 kontribusi nilai eigen dapat dilihat pada Tabel 3. Komponen $\mathrm{R}$ 
menghasilkan akurasi terbaik sebesar $70 \%$, sedangkan komponen $\mathrm{G}$ menghasilkan akurasi yang lebih baik dibanding komponen $\mathrm{R}$, yaitu sebesar 75\%. Pada komponen B, hasil akurasi yang diperoleh lebih rendah dibanding komponen sebelumnya dan menghasilkan akurasi terbaik sebesar $65 \%$. Komponen grayscale menghasilkan akurasi terbaik sebesar $70 \%$. Perbandingan grafik untuk setiap jenis Shorea pada semua kontribusi nilai eigen di komponen $\mathrm{R}$ dapat dilihat pada Gambar 4.

Pada Gambar 4, terlihat bahwa pada jenis Shorea javanica, lepida, dan platycados untuk setiap kontribusi nilai eigen menghasilkan akurasi yang sama. Berarti, kontribusi nilai eigen tidak terlalu berpengaruh pada jenis Shorea tersebut. Jenis Shorea johorensis mengalami penurunan di setiap kontribusi nilai eigen. Berdasarkan hal tersebut, dapat disimpulkan bahwa semakin besarnya kontribusi yang digunakan akan semakin menurunkan akurasi johorensis yang dihasilkan. Pada jenis Shorea materialis akurasi yang dihasilkan lebih rendah dibanding jenis Shorea lainnya pada setiap kontribusi nilai eigen.

Pada Gambar 5 dapat dilihat grafik hasil akurasi untuk setiap jenis Shorea pada semua kontribusi nilai eigen di komponen G. Pada komponen G ini, jenis Shorea yang memiliki akurasi yang sama di setiap kontribusi nilai eigen adalah jenis Shorea lepida dan platycados. Hal ini dapat dianalisis bahwa kontribusi nilai eigen tersebut tidak terlalu mempengaruhi hasil akurasi pada komponen G ini. Akurasi terendah pada komponen G ialah Shorea johorensis dan materialis. Kontribusi nilai eigen pada Shorea johorensis dan materialis memengaruhi perolehan akurasi. Pada kontribusi 99\% hasil akurasi lebih rendah dibanding dengan kontribusi lainnya.

Gambar 6 memperlihatkan akurasi untuk setiap jenis Shorea pada semua kontribusi nilai eigen di komponen B. Terlihat bahwa jenis Shorea johorensis dan materialis hanya dapat teridentifikasi ke dalam jenisnya sekitar 10\%, sedangkan Shorea materialis tidak dapat teridentifikasi sama sekali dengan kontribusi nilai eigen $85 \%$ dan 99\%. Jenis Shorea lepida dapat diklasifikasikan sebanyak 9 data uji yang benar sehingga hanya 1 yang salah diklasifikasikan. Shorea platycados menghasilkan akurasi yang tertinggi dan stabil di setiap kontribusi nilai eigennya. Pada jenis marcoptera, palembanica, dan seminis hasil akurasi yang diperoleh mengalami penurunan akurasi di setiap kenaikan kontribusi nilai eigennya.

Tabel 1 Ukuran vektor eigen

\begin{tabular}{cc}
\hline Kontribusi nilai eigen & Ukuran vektor eigen \\
\hline $85 \%$ & $182 \times 4$ \\
$95 \%$ & $182 \times 15$ \\
$99 \%$ & $182 \times 74$ \\
$100 \%$ & $182 \times 182$ \\
\hline
\end{tabular}

Tabel 2 Ukuran citra yang dipakai

\begin{tabular}{cc}
\hline Kontribusi nilai eigen & Ukuran citra \\
\hline $85 \%$ & $137 \times 4$ \\
$95 \%$ & $137 \times 15$ \\
$99 \%$ & $137 \times 74$ \\
\hline
\end{tabular}

Tabel 3 Hasil akurasi komponen R, G, B, dan grayscale pada setiap kontribusi nilai eigen

\begin{tabular}{cccc}
\hline \multirow{2}{*}{ Komponen warna } & \multicolumn{3}{c}{ Kontribusi nilai eigen (\%) } \\
\cline { 2 - 4 } & $85 \%$ & $95 \%$ & $99 \%$ \\
\hline $\mathrm{R}$ & 70 & 68 & 55 \\
$\mathrm{G}$ & 75 & 72 & 63 \\
$\mathrm{~B}$ & 64 & 65 & 51 \\
Grayscale & 70 & 69 & 62 \\
\hline Rata-rata & 69.8 & 68.5 & 57.8 \\
\hline
\end{tabular}


Gambar 7 menunjukkan grafik perbandingan akurasi jenis Shorea untuk setiap kontribusi nilai eigen pada citra grayscale. Pada perbandingan citra grayscale ini akurasi tertinggi dihasilkan oleh Shorea platycados dengan akurasi 100\%. Hasil akurasi terendah ada pada jenis Shorea johorensis dan materialis. Pada kontribusi nilai eigen 95\%, Shorea materialis tidak dapat teridentifikasi dengan benar sehingga menghasilkan akurasi terendah dengan nilai akurasi 0\%. Jenis Shorea johorensis dan materialis ini sulit teridentifikasi sebagai kelasnya sendiri dikarenakan ukuran Shorea tersebut memiliki kemiripan dengan jenis Shorea yang lainnya.

Dari percobaan yang telah dilakukan hasil terbaik terdapat pada komponen $\mathrm{G}$ dari citra RGB dan $k=3$ dengan kontribusi nilai eigen $85 \%$ yang menghasilkan $75 \%$. Berdasarkan ratarata akurasi pada Tabel 3, hasil rata-rata akurasi yang dihasilkan untuk setiap kontribusi nilai eigen semakin menurun setiap pertambahan kontribusi nilai eigen. Dapat disimpulkan pemilihan komponen warna citra, kontribusi nilai eigen dan nilai $k$ dapat mempengaruhi akurasi identifikasi suatu jenis Shorea. Penggunaan parameter yang tepat pada data latih dan data uji yang dipakai akan dapat menghasilkan akurasi yang baik. Selain ketiga faktor tersebut, faktor background dari citra yang digunakan dapat mempengaruhi perolehan akurasi, karena background dari citra daun yang digunakan dalam penelitian ini dari segi warna dan intesitas cahaya mempunyai perbedaan. Keseragaman background diharapkan dapat lebih meningkatkan akurasi yang dihasilkan. Pada penelitian ini komponen $G$ yang paling

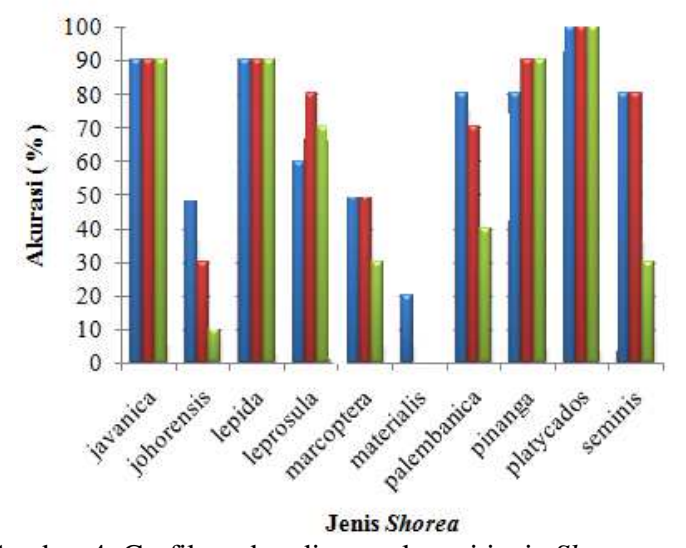

Gambar 4 Grafik perbandingan akurasi jenis Shorea untuk setiap kontribusi nilai eigen pada komponen R. Kontribusi nilai eigen: Biru $=$ $85 \%$, Merah $=95 \%$, Hijau $=99 \%$

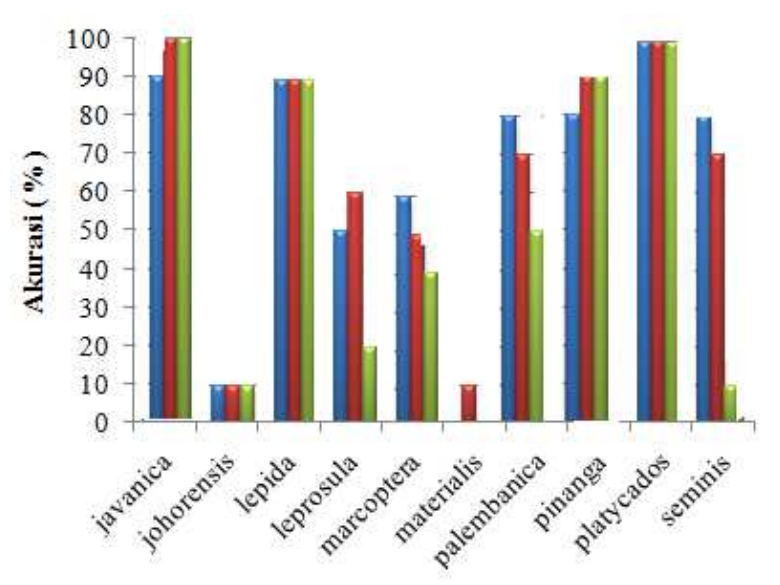

Jenis Shorea

Gambar 6 Grafik perbandingan akurasi jenis Shorea untuk setiap kontribusi nilai eigen pada komponen B. Kontribusi nilai eigen: Biru = $85 \%$. Merah $=95 \%$. Hiiau $=99 \%$

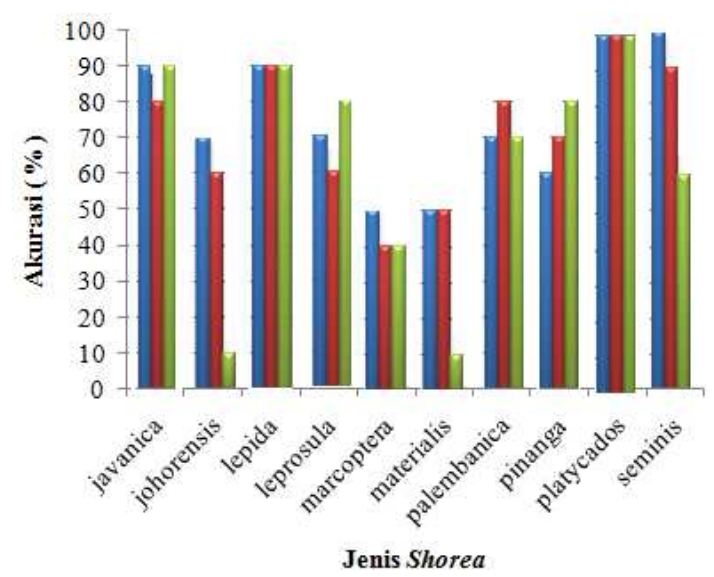

Gambar 5 Grafik perbandingan akurasi jenis Shorea untuk setiap kontribusi nilai eigen pada komponen G. Kontribusi nilai eigen: Biru = $85 \%$, Merah $=95 \%$, Hijau $=99 \%$

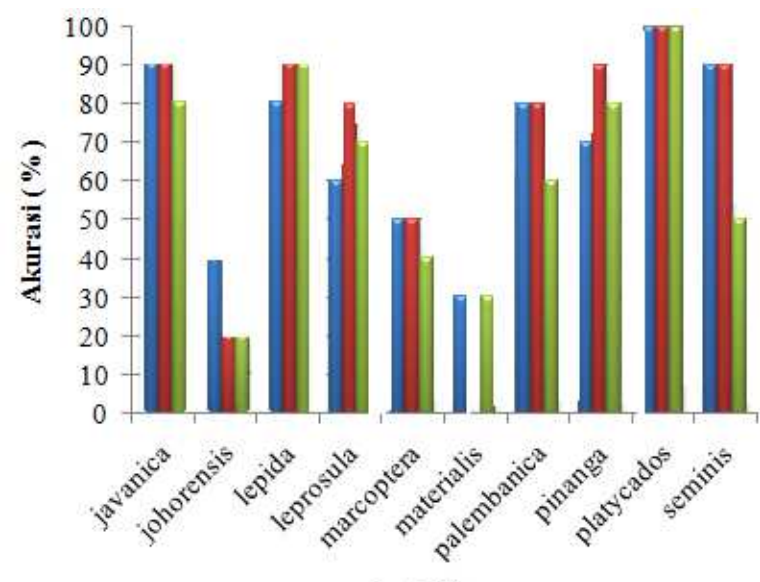

Jenis Shorea

Gambar 7 Grafik perbandingan akurasi jenis Shorea untuk setiap kontribusi nilai eigen pada citra grayscale. Kontribusi nilai eigen: Biru $=$ $85 \%$, Merah $=95 \%$, Hijau $=99 \%$ 
berpengaruh dalam menghasilkan akurasi terbaik. Hal ini dikarenakan data penelitian ini berobjek daun yang memiliki warna hijau sehingga pada komponen $\mathrm{G}$ hasil akurasi yang diperoleh lebih baik daripada komponen $\mathrm{R}, \mathrm{B}$, dan grayscale.

Jenis Shorea yang selalu memiliki akurasi yang tertinggi adalah Shorea platycados, pada komponen warna dan kontribusi nilai eigen serta nilai $k$ berapa pun selalu dapat teridentifikasi dengan benar hingga mencapai $100 \%$. Karena ukuran dari Shorea Platycados ini cenderung berbeda dengan jenis lainnya sehingga jenis Shorea jenis ini selalu dapat diidentifikasikan. Jenis Shorea Lepida dapat dengan tepat teridentifikasi ke kelasnya dengan akurasi 90\%. Pada Gambar 8 dapat dilihat gambar jenis Shorea yang tepat teridentifikasi dengan benar.

Pada Gambar 9 dapat dilihat gambar jenis Shorea yang sering salah dalam pengidentifikasian. Jenis Shorea javanica, johorensis, leprosula, marcoptera, materialis, palembanica, pinanga sering salah dalam pengidentifikasian karena ukuran Shorea tersebut memiliki kemiripan dengan jenis Shorea lainnya.

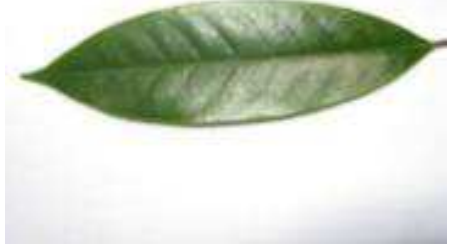

(a)

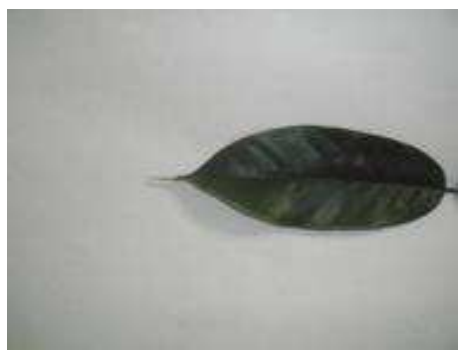

(b)

Gambar 8 Shorea Lepida (a) dan Platycados (b)

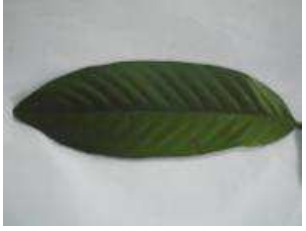

(a)

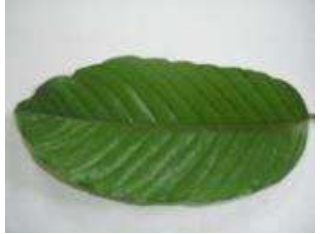

(e)

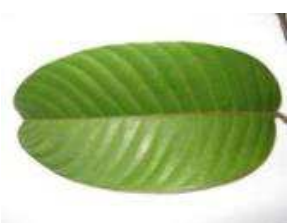

(b)

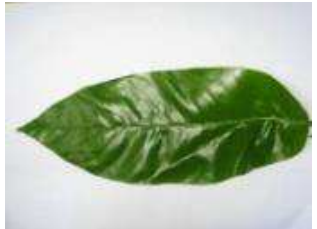

(f)

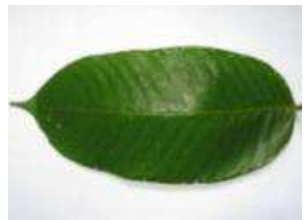

(c)

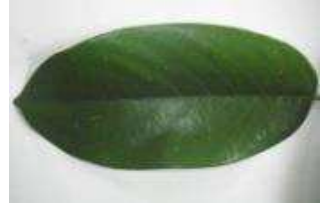

(g)

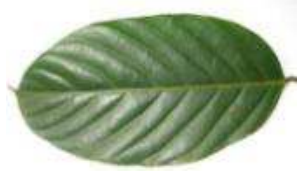

(d)

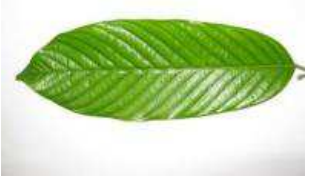

(h)

Gambar 9 Shorea javanica (a), johorensis (b), leprosula (c), marcoptera (d), materialis (e), palembanica $(\mathrm{f})$, pinanga $(\mathrm{g})$, seminis $(\mathrm{h})$

\section{Analisis Ragam Akurasi Percobaan}

Analisis ragam adalah suatu metode untuk menguraikan keragaman total data kita menjadi komponen-komponen yang mengukur berbagai sumber keragaman (Walpole 1988). Pada penelitian ini dilakukan analisis ragam dengan 3 faktor adalah nilai k, kontribusi, dan warna yang dapat dilihat pada Tabel 4 . Pada $\alpha=0.05$ dapat dilihat nilai $p$ pada Tabel 4 , faktor yang berpengaruh adalah nilai $\mathrm{k}$, kontribusi dan warna, sedangkan interaksi antara faktor tidak berpengaruh. Dengan demikian dapat disimpulkan bahwa pada penelitian ini nilai $\mathrm{k}$, kontribusi, dan warna mempengaruhi tinggi rendahnya akurasi percobaan tetapi interaksi antara faktor tidak berpengaruh. 
Tabel 4 Analisis ragam akurasi percobaan

\begin{tabular}{lrrrrr}
\hline Sumber & $\begin{array}{c}\text { Derajat } \\
\text { bebas }\end{array}$ & \multicolumn{1}{c}{ JK } & KT & F $_{\text {hitung }}$ & Nilai P \\
\hline Nilai k & 3 & 518.65 & 172.88 & 3.13 & 0.027 \\
Kontribusi & 2 & 6802.71 & 3401.35 & 61.49 & 0.000 \\
Warna & 3 & 3087.81 & 1029.27 & 18.61 & 0.000 \\
Nilai k*Kontribusi & 6 & 97.29 & 16.22 & 0.29 & 0.940 \\
Nilai k*Warna & 9 & 213.44 & 23.72 & 0.43 & 0.919 \\
Kontribusi Warna & 6 & 305.63 & 50.94 & 0.92 & 0.418 \\
Nilai k*Kontribusi*Warna & 18 & 404.37 & 22.47 & 0.41 & 0.986 \\
Galat & 192 & 10620.00 & 55.31 & & \\
Total & 239 & 22049.90 & & & \\
\hline
\end{tabular}

\section{SIMPULAN DAN SARAN}

\section{Simpulan}

Berdasarkan penelitian yang telah dilakukan dapat diambil kesimpulan bahwa akurasi pengenalan citra daun Shorea dengan menggunakan 2DPCA dan K-NN sebagai classifier dengan komponen $\mathrm{G}$ dari citra $\mathrm{RGB}$ dan $k=3$ serta pada kontribusi nilai eigen $85 \%$ menghasilkan rata-rata akurasi terbaik sebesar $75 \%$. Komponen warna yang paling berpengaruh dalam penelitian ini adalah komponen $\mathrm{G}$ dibanding komponen warna $\mathrm{R}, \mathrm{B}$, dan grayscale.

\section{Saran}

Penelitian ini masih memiliki beberapa kekurangan yang dapat diperbaiki pada penelitian selanjutnya. Beberapa saran itu di antaranya dengan menambahkan jumlah data untuk setiap jenis Shorea agar data yang digunakan lebih bervariasi. Menggunakan teknik klasifikasi lain yang dapat meningkatkan akurasi.

Penggunaan fitur warna selain RGB, seperti HSV. Pemberian bobot menggunakan algoritme genetika untuk masing-masing komponen RGB. Perlu dipertimbangkan juga terhadap penggunaan ukuran data asli pada penelitian selanjutnya, dikarenakan pada penelitian ini menggunakan ukuran data citra daun yang di-resize terlebih dahulu.

\section{DAFTAR PUSTAKA}

Newman MF, Burgess PF, Whitmore TC. 1999. Pedoman Identifikasi Pohon-pohon Dipterocarpaceae Jawa sampai Nugini. Bogor (ID): Prosea Indonesia.

Pratiwi. 2010. Pengembangan model pengenalan wajah dengan jarak euclid pada ruang eigen dengan 2DPCA [tesis]. Bogor (ID): Institut Pertanian Bogor.

Ramadhan IA. 2012. Identifikasi daun Shorea dengan backpropagation neural network menggunakan ekstraksi fitur discrete wavelet transform dan ekstraksi warna HSV [skripsi]. Bogor (ID): Institut Pertanian Bogor.

Rodríguez-Aragón LJ, Conde C, Serrano Á, Cabello E. 2005. Face verification advances using spatial dimension reduction methods: 2DPCA \& SVM. Di dalam: Roli F, Vitulano S, editor. Image Analysis and Processing-ICIAP 2005; Cagliari (IT), 2005 Sep 6-8. Berlin Heidelberg (DE): Springer. hlm 978-985.

Walpole RE. 1988. Pengantar Statistika Edisi ke-3. Jakarta (ID): PT Gramedia Pustaka Utama. Terjemahan dari Introduction to Statistic. New Jersey(US): Prentice-Hall.

Yang J, Zhang D. 2004. Two dimensional PCA: a new approach to appearance based face representation and recognition. IEEE Trans Pattern Anal Mach Intell, 26(1):131-137. 